\title{
A distributed information system prototype to detect and monitor the Hazardous Material Transport on the road in the territory of Nice-Imperia-Ventimiglia
}

\author{
M. Benza ${ }^{1}$, C. Bersani ${ }^{1,2}$, E. Garbolino ${ }^{3}$, D. Giglio ${ }^{1}$, S. Olampi ${ }^{3}$, \\ R. Sacile ${ }^{1}$, A. Tomasoni ${ }^{1}$ \& E. Trasforini ${ }^{1}$ \\ ${ }^{I}$ DIST - Università di Genova - clo Polo Savonese, via Cadorna 7, \\ 17100 Savona, Italy \\ ${ }^{2}$ CIELI, Centro di Eccellenza sulla Logistica Integrata, \\ Università di Genova,via Bensa 1, 16024 Genova, Italy \\ ${ }^{3}$ ARMINES, rue Claude Daunesse BP 207, 06904 Sophia Antipolis, \\ France
}

\begin{abstract}
This paper aims to present a Decision Support System (DSS) for the detection and monitoring of Hazardous Material (hazmat) transportation on the road infrastructure Nice-Imperia-Savona between France and Italy developed in the TMD-NIS Interreg IIIA Alcotra Project. The final objective of the TMD-NIS project is to determine the most effective information and communication technologies and common operation strategies applicable in hazmat management in order to minimize the hazmat transport risk and to improve the road infrastructure safety conditions. An integrated and comparative assessment of two alternative technologies has been performed by the partners of the project: an image processing system to identify the ONU codes on the hazmat plates installed on each truck has been tested in France, while an on-board computer system to store and transmit information related to the hazmat physical conditions, vehicle's locations and performance measures has been implemented in Italy. The collaboration between the different research institutions and the complementarities of the two specific approaches to define and monitor the hazmat vehicle flows allow comparison and validation of the acquired data related to the type, the amount and the itineraries of the hazmat vehicles which cover the trans-border road infrastructures daily. At present, the TMD-NIS project also provides a GIS utility, available on the web, to track in real-time hazmat vehicles, to analyse data about hazmat flows and to visualize the risk index for the highway from the toolbar barriers of St. Isidore (Nice) to the Ventimille.
\end{abstract}

Keywords: Hazardous Material Transport, Decision Support System, risk analysis, information and communication technologies. 


\section{Introduction}

Hazardous materials (hazmat) are employed in many industrial activities in each European country. Each phase of the supply chain which involves hazmat, such as production, storage, transport and distribution inherits many risks for population, transport infrastructures and environment. For this reason, in order to reduce accidents and dangerous events, it is necessary to integrate risk analysis and prevention measures into the hazmat transport management.

According to Eurostat [1], the total road freight transport in the EU amounted to 1365 billion tons per kilometres in 2002 and the $5 \%$ of all goods transported are hazmat. In Italy, 11.406 million of tons per $\mathrm{km}$ of hazmat transit on the Italian road infrastructure while 8.825 transit in the France territories. This kind of transport represents about $6.6 \%$ of the total freight transport on road with over than 600 million of vehicle per $\mathrm{km}$ in each country. Those trends underline the predominant role of transport activities for the growth of European cooperation and the consequent increase of business in this sector for the future. TMD-NIS is a project whose general aim is to reveal the state of the art, to compare and to verify the validity of existent methodologies and technologies applied in the road transport management with special reference to problems related to tracking and tracing of hazmat trucks and risk management on the trans-border region between Italy and France.

\section{Hazmat transport: state of the art}

Hazmat transport is subject to special requirements to eliminate or minimize the risk of injuring people, damaging immovable and movables property and the environment. Those international regulations, which itemized hazmat in several categories according to their danger, are collected in the European Agreement concerning the International Carriage of Dangerous Goods by Road (ADR). The ADR 2005 is based on the UN Recommendations on the hazmat transport as regards the listing and classification of hazmat, their marking and labelling and packaging standards. It also contains much more detailed provisions as regards the types of packaging which have to be used, the consignment procedures, transport equipment and above all transport operation as tracking and tracing of the hazmat vehicles, training of drivers, emergency procedures and placarding of vehicles. The ADR is intended primarily to increase the safety of international transport by road and it is also effective on the territory of the 38 Contracting Parties. Due to the complexity of the problem and the new directives imposed by the ADR, the decisional approach of the TMD-NIS project aims, generally, to implement a Decision Support System (DSS) concentrated on the following thematic priorities

- $\quad$ hazmat real-time tracking and vehicle monitoring

- detection and evaluation of the hazmat flows on the specific road infrastructure

- $\quad$ risk definition on the routes covered by trucks. 
The growing of the hazmat transport demand and, in the same way, the aware concerning the harmful impact of hazmat accident effects, have influenced many hazmat distribution companies toward more balanced and sustainable transport solutions. At present, the Intelligent Transport System (ITS) represents the best application of computer and communications technologies to hazmat transport problems to arise safety and security in each distribution operations. The different technological approaches, to detect and to monitor hazmat traffic, tested in the TMD-NIS project, have been identified as two effective examples to assist the hazmat road management. Those intelligence advices and new technologies, in fact, are able to collect and transmit data so to provide relevant and timely information to road managers and users.

\section{Decisional problem definition}

In the case of hazmat transport on road, risk management is particularly complex mainly due to the fact that hazmat trucks are moving on the territory, and their current position and their forthcoming routing are very often unknown and subject to several time-dependent decision factors made by the driver and by the transport company, mainly on cost/time basis (Atzei et al., [2]).

\subsection{Decision makers}

Three main categories of Decision Maker (DM) can influence the decisions on the routing followed by a fleet of vehicles delivering hazmat by the road infrastructure displaced over one or several territorial regions:

- Territorial Institution DM, which focuses more on the hazmat transport system from a territorial point of view, for example aiming to guarantee safety on population, properties and environment in the neighbourhood of the road infrastructure.

- Distribution Companies DM, which aim to minimise cost/time in the hazmat distribution guarantying deliveries for their customers. Distribution companies are usually represented by the planner for the fleet routing. Trucks adapt their behaviour to the dynamics of the road infrastructure they transit on, according to the route plan they received from the company they depend on and from the direct experience of the driver about traffic and infrastructure condition.

- Road Infrastructure DM which focuses more on the infrastructure, with the aim to maximise the efficiency of the service, avoiding queues due to accidents, maximizing profits incomes from customers and minimizing costs due to maintenance.

In this prospective, the partners of the TDM-NIS project have involved institutions and a distribution company so to analyse the different rights, duties, exigencies and roles for the hazmat transport on road. 


\section{Decision support system architecture}

The information system developed in the TMD-NIS project is based on three different layers by the integration of hardware and software systems allowing the effective exploitation of different methodologies. The information system architecture consists in

1. detection and monitoring system which integrates an active tracking system installed on-board of each monitored truck and a passive detection system for the hazmat identification installed on the road infrastructure.

2. a common database to store information acquired by both the active and passive systems

3. risk definition module

4. a web-GIS (Geographic Information Systems) user interface.

\subsection{Detection and monitoring of hazmat transport vehicles}

\subsubsection{Optical recognition system}

An optical recognition system for the identification of hazmat vehicles has been developed. The danger of the truck can be signalized in two different ways: a plate containing danger code or several plates with danger symbols. The plate with the danger code is orange and rectangular and contains two numbers: the first number represents the transported hazmat (ONU code) while the second one represents the hazard associated with the delivered material (hazard code). The symbols which define the risk can be in different colors and model. The project principally concentrates on the identification of the plate danger code. A prototype of an image acquisition system has been set up in a toll-bar St' Isidore, near Nice (France). The system includes a video camera installed in each passage of the highway toolbar dedicated to the heavy vehicles and a server used to store the acquired images. After the acquisition of the image, a software treats the picture in order to detect and to identify the numbers inside the orange rectangle. The algorithm is based on five steps

- Treatment of the image

- Identification of the image form

- Filtrage

- Harris Corner Detector

- Number Extraction

The algorithm isolates, in the image, the orange colour related to the danger plate and corrects the rectangular form due to deviation of the prospective of the photo. After a filtering phase, the Harris Corner Detector algorithm is applied to the image in order to define the sequence of the numbers and, finally, an OCR application (Optical Character Recognition) identifies the related hazardous material delivered by the truck.

\subsubsection{Monitoring of hazmat transport vehicles}

In order to perform a real time hazmat flows monitoring, each vehicle is equipped with different telematic technologies: an "on-board computer" located in the trailer and an "in -cabin" system located in the tractor. 
The on-board computer consists in a specific device called "concentrator" which stores information and uses a GPS/GPRS module to identify the location of the vehicle and to send data to the control centre. The concentrator, in fact, acquires data by the peripheral tools (analogic/digital sensors, CAN-BUS, electronic counter) connected to each monitored mechanical element of the truck. It is able to collect information related to the amount and to the physical condition of delivered hazmat product such as temperature or pressure but also vehicle's performance measures such as speed, odometer value, number of brakings, fuel consumption, hours of service or inclination of the tank. Besides the concentrator can capture and archive all kind of event occur during the trip of the truck: the types of events can include transaction time and date, transaction type such as load, release or delivery.

Every message sent to the server also contains some fundamental information such as driver name, truck coordinates and identifier number.

The "in-cabin" system, located in the trailer, provides a user interface by a mobile phone at driver's disposal and permits transmission of order assignments and status messaging between the control centre and the driver. Both of the modules are designed to use satellite-based global positioning system (GPS) technology to provide current vehicle position, including latitude and longitude readings and a GPRS mobile communication system in order to transmit the collected information to the central server. This kind of technologies provides to the driver or/and the hazmat distribution company information related to vehicle operations; this operation improves safety performance of vehicles and causes a consequent improvement of the safety on the road infrastructure covered by the vehicle during their tour.

\subsection{Common database}

The information collected in the concentrators, installed on the monitored vehicles, and the data coming from the optical recognition systems are transmitted to a server and stored in a common database. Besides, this kind of database allows one to create useful statistics about the flows of hazmat vehicle and to the related risk index on the considered territories. The database consists of three modules with different functions. The first database, the "control database", stores information provided in real-time by the detection and monitoring system. The "historical database" contains the information acquired in the past by both the active and passive systems. It provides data to the web server and to the application server to allow the computation of the risk indices, implemented in the DSS, related to the covered links of the considered infrastructures.

The "registry database" stores information characterizing the different elements that compose the information system architecture. The main characteristics include the typologies and technological parameter of the monitored trucks and the geographical location of the toll-bar where the optical recognition systems are installed. 


\subsection{Risk definition module}

The risk, usually, refers to the probability of a specific and potential damage caused by an occurred accident which involves hazmat. In this paper, the risk is computed as an index which defines the danger to transit on a specific road infrastructure taking into account directly the static, environmental and dynamic features of the territory interested by a potential accidental event. This approach defines the risk as a spatial and time dependent phenomenon specific for the area where the risk-index has been assessed. In particular, in this paper the definition of the risk is computed in function of

- the population living around the area covered by the road infrastructure (Benza et al. [3], Casazza et al. [4]) and

- the expected accident frequency per vehicle which depends on the basic accident frequency (accident $\mathrm{km}^{-1}$ vehicle $^{-1}$ year ${ }^{-1}$ ) and on six amplifying/mitigating parameters (Fabiano et al., [5]).

Specifically, for each considered road segment, four parameters are related to intrinsic road characteristics (turns, slope, number of lanes, bridge/tunnel), and two parameters related to meteorological and traffic conditions.

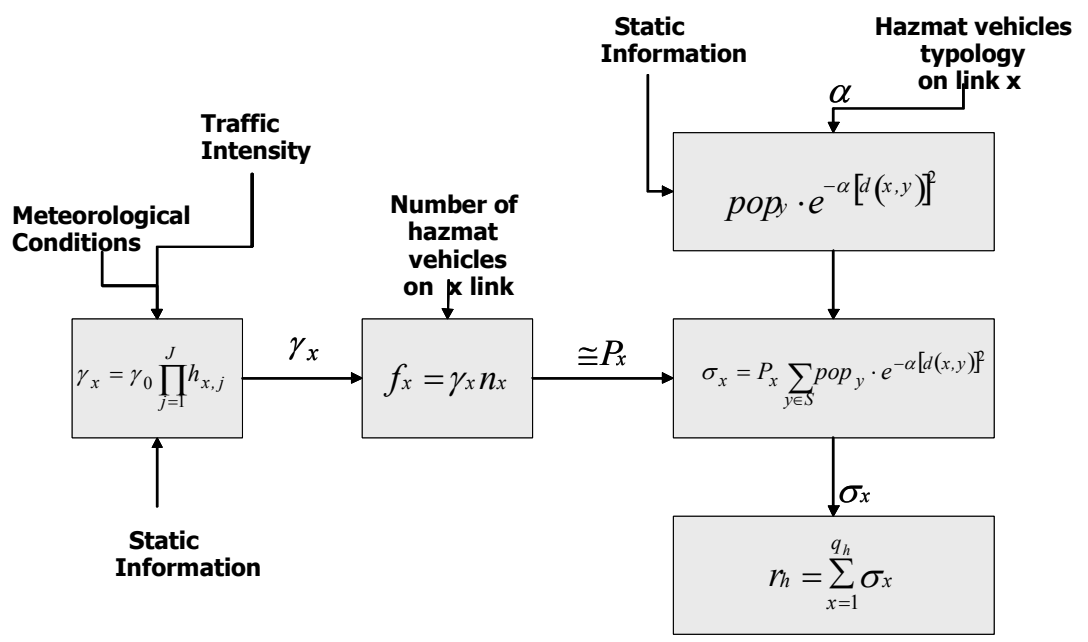

Figure 1: A scheme that summarizes the procedure for the hazmat transport risk assessment on a generic link $i$.

\subsection{Web-GIS user interface}

At the present, the DSS can be accessed by a web-GIS interface which provides the possibility to track in real-time hazmat transports and to analyse data about hazmat flows and risk indices. The web-based GIS user interface consists in three different parts: "visualize", "telemetry" and "infrastructure". In the first part, "visualize", the system provides real-time Navteq digital maps based on the 
"Microsoft Mappoint web service". The user can select a specific truck to monitor and the time horizon to analyse. According to the user's request, the web-based GIS module requires data from the database server related to the selected truck and dialogues with the web service to load the necessary map to visualize the current position.

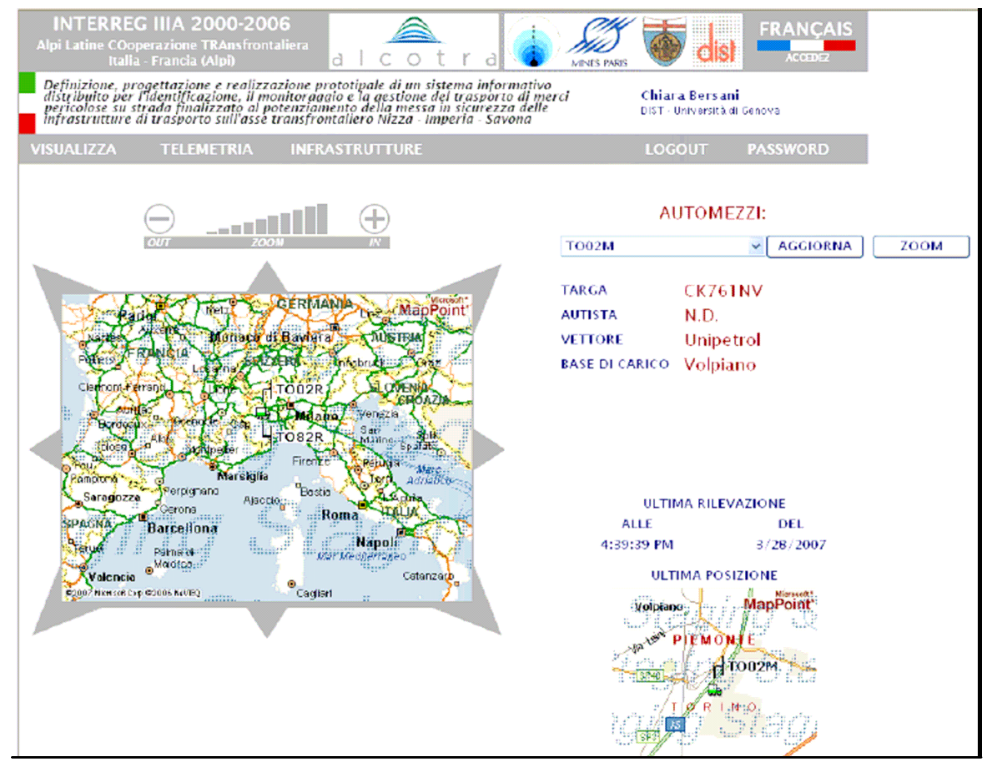

Figure 2: Web-GIS user interface.

Selecting the "telemetry" option, the user can consult the historical information related to each monitored hazmat vehicle equipped with an "onboard" system and to analyse the performance of each specific registered event. In the "infrastructure" option, the system provides the map information related to the hazmat traffic flows localized at a controlled toll-bar barrier near Nice. In particular, the user can choose the ONU code, which describes the transported material, or the hazard code to analyse the flow of trucks which have delivered the selected hazardous material transited on the toll-bar of St'Isidore near Nice.

Specifically, the graphic user interface displays the risk index associated to each road link, computed as described in paragraph 4.3. Alarm index are shown for the 12 road segments in the Nice districts near the toll-bar barriers of St. Isidore (Nice) to the frontier France-Italy. Each sector of the highway is characterized by a coloured segment to identify the different risk indexes, red for high risk, yellow as medium risk and green as low risk. A second option of this web page provides graphs about statistics related to the hazmat flows on the considered territories. The user can select the hazardous material name or ONU code and the time horizon to base his analysis. 


\section{Results and future development}

The hazmat transport risk model defined in the DSS has been implemented for a pilot area localized in the highway A8 from the toll-bar St' Isidore to Ventimille, on the Italy's border with France. This analysed section of the highway has been split in 12 links of tree kilometres and for each link the model explained in Benza et al. [3] and in Casazza et al. [4] has been applied. The amplifying/mitigating parameters have been computed taking into account the ranges proposed by Fabiano et al. [5] for each of them. The basic frequency (relevant to accidents involving hazmat trucks) has been evaluated as the $5 \%$ of the frequency accident related to heavy traffic specific for each considered road segment of the highway. At present time, four of the six parameters proposed by Fabiano et al. [5] have been taken into account in the case study, whereas the insertion of the remaining two parameters (namely, the ones relevant to meteorological and traffic conditions) is one of the main goals of the following phases of the project. The amplifying/mitigating parameters for the case study result:

Table 1: Amplifying/mitigating parameters for the pilot area.

\begin{tabular}{|c|c|c|c|c|c|}
\hline km of the highway $A 8$ & $\begin{array}{l}h 1 \\
\text { Straight } \\
\text { /curve road }\end{array}$ & $\begin{array}{l}h 2 \\
\text { Slope } \\
\text { road } \\
\end{array}$ & $\begin{array}{l}h 3 \\
\text { Lanes for } \\
\text { each carriage }\end{array}$ & $\begin{array}{l}h 6-a \\
\text { Tunnel } \\
\text { presence }\end{array}$ & $\begin{array}{l}h 6-b \\
\text { Bridge } \\
\text { presence }\end{array}$ \\
\hline \multicolumn{6}{|l|}{ Nice St'Isidore-Nice Est } \\
\hline km 190-193 of the highway A8 & 1,00 & 1,30 & 1,20 & 0,80 & 1,00 \\
\hline km 193-196 & 2,20 & 1,20 & 1,20 & 0,80 & 1,00 \\
\hline km 196-199 & 1,00 & 1,30 & 1,20 & 0,80 & 1,20 \\
\hline \multicolumn{6}{|l|}{ Nice Est- La Turbie } \\
\hline km 199-202 & 1,00 & 1,20 & 1,20 & 0,80 & 1,00 \\
\hline km 202-205 & 1,00 & 1,00 & 1,20 & 1,00 & 1,00 \\
\hline km 205-208 & 1,00 & 1,00 & 0,80 & 1,00 & 1,00 \\
\hline \multicolumn{6}{|l|}{$\begin{array}{l}\text { La Turbie-Roquebrune /Cap } \\
\text { Martine }\end{array}$} \\
\hline km 208-211 & 1,30 & 1,00 & 0,80 & 0,80 & 1,00 \\
\hline km 211-214 & 1,00 & 1,00 & 0,80 & 0,80 & 1,00 \\
\hline km 214-216 & 1,00 & 1,00 & 0,80 & 0,80 & 1,20 \\
\hline \multicolumn{6}{|l|}{$\begin{array}{l}\text { Roquebrune/Cap Martine- } \\
\text { border Ventimille }\end{array}$} \\
\hline km 216-219 & 1,00 & 1,00 & 0,80 & 0,80 & 1,20 \\
\hline km 219-222 & 1,00 & 1,00 & 0,80 & 0,80 & 1,20 \\
\hline km 222-224 & 1,00 & 1,00 & 0,80 & 1,00 & 1,20 \\
\hline
\end{tabular}

The obtained risk indices highline that only the first link, from Nice St' Isidore to Nice Est toll-bars $(9 \mathrm{~km})$ on the highway A8, results at "high risk". In this case, in fact, the parameters related to static characteristics of the road assume critical values and the frequency of accident which involved heavy vehicle is about 0,4 for year. 
As future development, the project will focus on the integration in the transport risk model of the two parameter related to dynamic elements referred to meteorological conditions and to traffic conditions.

Weather conditions and traffic intensity information, acquired in real time by web or by specific tools located on the infrastructures, could be the base to create a central unit for the hazmat transport management on road. A new network to support hazmat distribution company DMs, road infrastructure DMs and, above all, the territorial institution DMs, could be realized integrating the monitoringidentification system proposed in the TMD-NIS project with a the real-time accident warning system and a intelligent real-time route planning system to optimize routing of hazmat vehicle in order to improve the security on the transport infrastructures for common users and environmental.

\section{Acknowledgements}

This work has been partially financed by the Interreg Alcotra project n. 176 and by Regione Liguria. We also thank Savona and Imperia Provinces, Prefecture 06 (France), ESCOTA, the city of Nice and Autostrada dei Fiori. A special thank to PRAOIL S.p.A. which gave a fundamental support from an operational viewpoint providing the possibility to track their vehicle on the considered territories of the project.

\section{References}

[1] Eurostat, http://epp.eurostat.ec.europa.eu/.

[2] Atzei, F., Giglio, D., Minciardi, R., Paolucci, M., Pizzorni, D., Sacile, R., Trasforini, E., Vicini, G., 2004. Instradamento dinamico basato sul rischio nel trasporto di merci pericolose su strada, Atti del Convegno VGR 2004, Pisa.

[3] Benza M., Bersani C., Casazza R., Garbolino E., Giglio D., Olampi S., Sacile R. e Trasforini E.,'Definizione, progettazione e realizzazione prototipale di un sistema informativo distribuito per l'identificazione, il monitoraggio e la gestione dei flussi veicolari di merci pericolose"- Atti convegno VGR 2006 - Conferenza sulla Valutazione e Gestione del Rischio negli Insediamenti Civili e Industriali - ISBN 88-6019-061-4.

[4] Casazza, R., Garbolino, E., Olampi, S., Bersani, C., Trasforini, E., Giglio, D., and Sacile, R. "Detection and Monitoring of Hazardous Material Transport on road between France and Italy: objectives, methodology and first results.", Safety and Reliability for Managing Risk, C. Guedes Soares \& E. Zio Editors, vol. 3, pp. 2659-2666, (2006).

[5] Fabiano B., F. Currò, E. Palazzi and R. Pastorino (2002). A framework for risk assessment and decision-making strategies in dangerous good transportation, Journal of Hazardous Materials, 93, 1-15.

[6] Casazza R., Olampi S., Napoli A., A sensor based decision support system for the hazmat transport risk, UDMS2006, 2006 
[7] Giglio D., R. Minciardi, R. Rudari, A. Tomasoni, D. Pizzorni, R. Sacile and E. Trasforini (2004) Towards A Decision Support System for Real Time Risk Assessment of Hazardous Material Transport on Road". In Pahl-Wostl, C., Schmidt, S. and Jakeman, T. (eds) iEMSs 2004 International Congress: "Complexity and Integrated Resources Management". International Environmental Modelling and Software Society, Osnabrueck, Germany. 